\title{
Brain imaging of pain: state of the art
}

This article was published in the following Dove Press journal:

Journal of Pain Research

8 September 2016

Number of times this article has been viewed

\section{Debbie L Morton \\ Javin S Sandhu \\ Anthony KP Jones}

Human Pain Research Group, Institute of Brain, Behaviour and Mental Health, University of Manchester, Manchester, UK
Correspondence: Anthony KP Jones Human Pain Research Group, School of Translation Medicine, University of Manchester, Clinical Sciences Building Salford Royal NHS Foundation Trust Salford, M6 8HD, Manchester, UK

Email anthony.jones@manchester.ac.uk
Abstract: Pain is a complex sensory and emotional experience that is heavily influenced by prior experience and expectations of pain. Before the development of noninvasive human brain imaging, our grasp of the brain's role in pain processing was limited to data from postmortem studies, direct recording of brain activity, patient experience and stimulation during neurosurgical procedures, and animal models of pain. Advances made in neuroimaging have bridged the gap between brain activity and the subjective experience of pain and allowed us to better understand the changes in the brain that are associated with both acute and chronic pain. Additionally, cognitive influences on pain such as attention, anticipation, and fear can now be directly observed, allowing for the interpretation of the neural basis of the psychological modulation of pain. The use of functional brain imaging to measure changes in endogenous neurochemistry has increased our understanding of how states of increased resilience and vulnerability to pain are maintained. Keywords: fMRI, PET, EEG, arthritis, fibromyalgia

\section{Introduction: neuroimaging of pain and plasticity and the areas of the brain involved}

The poor relationship between regional tissue damage and pain experienced by patients $^{1-3}$ has led from pain being investigated as a localized phenomenon to a more complex process, including the central processing of the brain. This coincided with new techniques that allowed visual images to be derived from the activity of the brain, known as functional brain imaging. Despite extensive studies, no single area of the brain has been determined as solely responsible for pain processing. There is no pain center but instead a complex network of brain regions often termed the pain matrix (Figure 1), as originally conceptualized by Melzack and Wall. ${ }^{4,5}$ This matrix consists of multiple regions that in themselves are not only associated with pain but also involved in other sensory, motor, and cognitive functions where information is often processed in parallel. The consciousness of pain seems to appear at the later stages of pain processing when the neural information is being integrated across multiple regions of the cortex. ${ }^{6}$ Analysis of experimental pain neuroimaging shows six areas of the brain that consistently respond to acute pain and are believed to play an important role in the sensory-discriminative, cognitive, and affective aspects of pain processing. These are the thalamus, the insular cortex (IC), the primary and secondary somatosensory cortices (SI and SII), the anterior cingulate cortex (ACC), and the prefrontal cortex (PFC). ${ }^{7}$ These areas differ depending upon factors such as imaging modality, statistical analysis, psychological state, and type of pain elicited. Functional neuroimaging of 


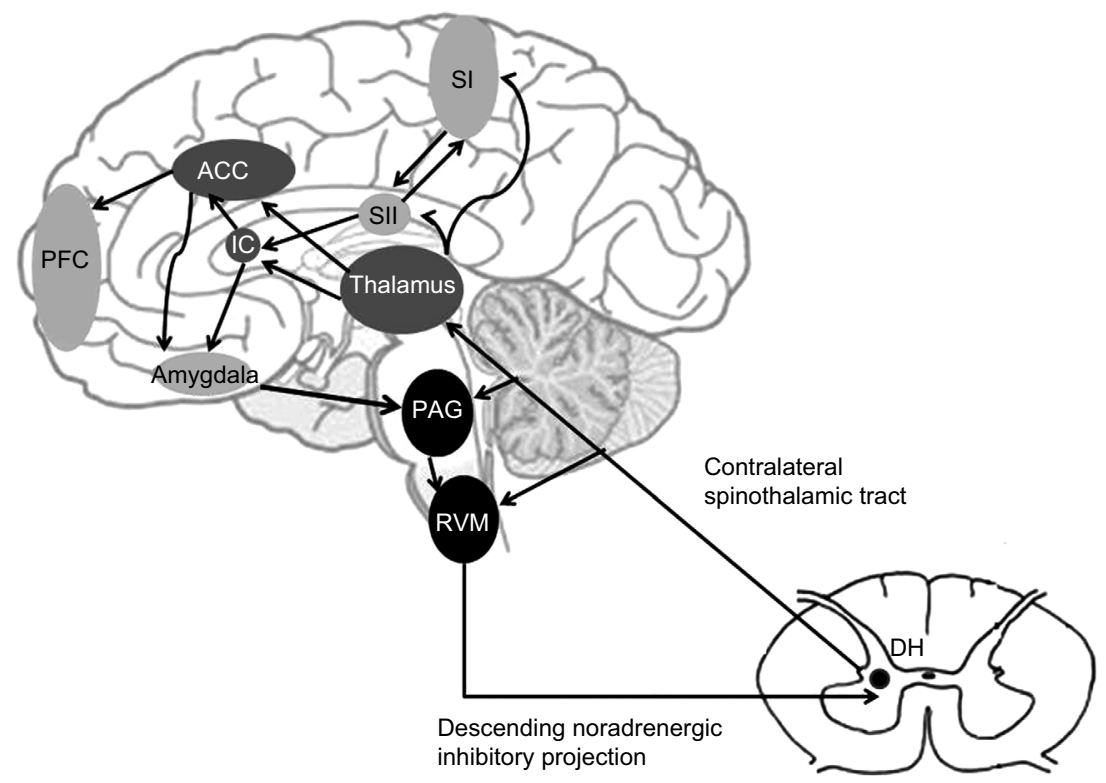

Figure I A schematic representation of pain modularity circuitry and the pain matrix.

Notes: Nociceptive inputs enter the spinal DH through primary afferent fibers that synapse onto transmission neurons. The projection fibers ascend through the contralateral spinothalamic tract targeting the thalamus, and collateral projections also target mesencephalic nuclei, including the RVM and the midbrain PAG. In the pain matrix, there are two complementary pathways through which pain processing takes place. The medial pathway (dark gray) projects from the medial thalamus to the ACC and IC and processes the affective-motivational component of pain (ie, unpleasantness). The lateral pathway (light gray) projects from the lateral thalamus to the primary and secondary somatosensory cortices (SI and SII) and IC and processes the sensory-discriminative aspect of pain (ie, location and intensity). Increased activation of the PFC is related to decreased pain affect purportedly by inhibiting the functional connectivity between the medial thalamus and the midbrain. Descending projections from the hypothalamus (not shown), amygdala, and rACC feed to the midbrain PAG and to the medulla. Neurons within the RVM project to the spinal or medullary DH to inhibit pain experience. (c) Springer Science+Business Media, LLC 2012. Reproduced with permission of Springer. Jones AK, Huneke NT, Lloyd DM, Brown CA, Watson A. Role of functional brain imaging in understanding rheumatic pain. Curr Rheumatol Rep. 2012;14(6):557-567. ${ }^{36}$

Abbreviations: DH, dorsal horn; RVM, rostral ventral medulla; PAG, periaqueductal gray; ACC, anterior cingulate cortex; IC, insular cortex; PFC, prefrontal cortex; rACC, rostral anterior cingulate cortex.

pain has been previously reviewed, focusing specifically on positron emission tomography (PET) and functional magnetic resonance imaging (fMRI) studies ${ }^{8}$ and neuropathic pain. ${ }^{9}$ This review provides a general overview of current neuroimaging techniques and the central processes of pain perception in healthy subjects and patients with chronic pain conditions. How the use of functional imaging can encourage and aid the development of new therapies is also explored.

\section{Imaging techniques used: technology overview}

The advent of functional neuroimaging technologies has been likened to the human genome project in their potential for advancing our scientific knowledge ${ }^{10}$ and also their potential for false-positive results. ${ }^{11,12}$

Our understanding of the neural basis of pain has been substantially increased as a result of the development of functional neuroimaging techniques (Table 1). Functional neuroimaging is based upon being able to measure changes in neuronal activity by measuring alterations in either aspects of metabolism (ie, blood flow, volume, oxygen, or glucose metabolism) or one aspect of neurochemistry (ie, neurotransmitter precursor uptake or receptor binding ${ }^{13}$ ). The most commonly used techniques depend on the premise that increased brain activity leads to increased energy metabolism and a disproportionate increase in regional cerebral blood flow $(\mathrm{rCBF}) .{ }^{14}$

\section{fMRI and related modalities}

fMRI is one of the most commonly used imaging methods in pain research. fMRI indirectly measures brain activity by detecting associated changes in blood flow (hemodynamic response). ${ }^{15}$ In its primary form, fMRI uses the blood-oxygenlevel-dependent (BOLD) contrast imaging, which is indicative of synaptic activity. ${ }^{16}$ The BOLD technique evaluates the difference in magnetic susceptibility between the oxygenated blood (oxyhemoglobin) required by active neurons and the resultant deoxygenated blood (deoxyhemoglobin) and creates the fMRI signal from this difference. ${ }^{17,18}$ The fMRI BOLD technique is an extremely useful measure in acute and experimental pain where there are short periods of pain followed by short periods that are pain free, causing a rapidly changing hemodynamic response. This allows the study of acute pain response in pain-free volunteers and pain patients with chronic pain but is not well suited to the monitoring of responses to changes in chronic pain. For persistent pain 
Table I A summary of the features and advantages and disadvantages of the neuroimaging methods discussed in this review

\begin{tabular}{|c|c|c|c|c|c|}
\hline $\begin{array}{l}\text { Neuroimaging } \\
\text { method }\end{array}$ & Nature of signal & $\begin{array}{l}\text { Spatial } \\
\text { resolution }\end{array}$ & $\begin{array}{l}\text { Temporal } \\
\text { resolution }\end{array}$ & Advantages & Disadvantages \\
\hline fMRI - BOLD & $\begin{array}{l}\text { Stimulus evoked hemodynamic } \\
\text { activity in the brain as } \\
\text { determined by oxyhemoglobin } \\
\text { and deoxyhemoglobin }\end{array}$ & $\mathrm{mm}$ & Seconds & $\begin{array}{l}\text { Good spatial resolution } \\
\text { Can measure cognitive } \\
\text { processes }\end{array}$ & $\begin{array}{l}\text { Indirect measure of } \\
\text { neuronal activity } \\
\text { Use of artificial stimulus } \\
\text { may not reflect clinical } \\
\text { pain }\end{array}$ \\
\hline$f M R I-A S L$ & $\begin{array}{l}\text { Cerebral blood flow using } \\
\text { magnetically labeled endogenous } \\
\text { water in the blood acting as a } \\
\text { diffusible tracer }\end{array}$ & $\mathrm{mm}$ & Minutes & $\begin{array}{l}\text { Task or pain stimulus is not } \\
\text { needed } \\
\text { Representative of ongoing } \\
\text { clinical pain }\end{array}$ & $\begin{array}{l}\text { Indirect measure of } \\
\text { neuronal activity } \\
\text { Few studies in pain to } \\
\text { test feasibility }\end{array}$ \\
\hline MRI-DTI & $\begin{array}{l}\text { Diffusion of water through } \\
\text { white matter }\end{array}$ & $\mathrm{mm}$ & Weeks-years & $\begin{array}{l}\text { Increase understanding of } \\
\text { brain networks }\end{array}$ & $\begin{array}{l}\text { Suffers from data } \\
\text { artifacts }\end{array}$ \\
\hline MRI - structural & $\begin{array}{l}\text { Structural information } \\
\text { about the gray matter and } \\
\text { white matter using VBM }\end{array}$ & $\mathrm{mm}$ & Weeks-years & $\begin{array}{l}\text { Provides excellent structural } \\
\text { information } \\
\text { Allows assessment of disease } \\
\text { over time }\end{array}$ & $\begin{array}{l}\text { MRI scanners are } \\
\text { expensive }\end{array}$ \\
\hline NIRS & $\begin{array}{l}\text { Stimulus-evoked hemodynamic } \\
\text { response determined by } \\
\text { differences in NIR light } \\
\text { absorption spectra }\end{array}$ & $\mathrm{mm}$ & Seconds & $\begin{array}{l}\text { More portable than } \mathrm{fMRI} \\
\text { Can measure cognitive } \\
\text { processes }\end{array}$ & $\begin{array}{l}\text { Can only scan cortex } \\
\text { Use of artificial stimulus } \\
\text { may not reflect clinical } \\
\text { pain }\end{array}$ \\
\hline PET & $\begin{array}{l}\text { Cerebral blood flow, oxygen } \\
\text { uptake, and glucose metabolism } \\
\text { using specific radionucleotides }\end{array}$ & $\mathrm{mm}$ & Minutes & $\begin{array}{l}\text { Measures cerebral } \\
\text { metabolism } \\
\text { Ligand and drug binding }\end{array}$ & $\begin{array}{l}\text { Expensive } \\
\text { Uses radioactive } \\
\text { tracer limiting repeat } \\
\text { application }\end{array}$ \\
\hline EEG & $\begin{array}{l}\text { ERPs detected by voltage changes } \\
\text { resulting from neuronal } \\
\text { information transfer }\end{array}$ & $\mathrm{mm}-\mathrm{cm}$ & Milliseconds & $\begin{array}{l}\text { Lower cost } \\
\text { Portable } \\
\text { Widely available } \\
\text { Signals generated directly } \\
\text { from neural activity }\end{array}$ & $\begin{array}{l}\text { Use of artificial stimulus } \\
\text { may not reflect clinical } \\
\text { pain } \\
\text { Source localization is } \\
\text { difficult }\end{array}$ \\
\hline MEG & $\begin{array}{l}\text { ERPs detected by magnetic field } \\
\text { disturbances resulting from } \\
\text { neuronal information transfer }\end{array}$ & $\mathrm{mm}$ & Milliseconds & $\begin{array}{l}\text { Signals generated directly } \\
\text { from neural activity } \\
\text { Good spatial resolution }\end{array}$ & $\begin{array}{l}\text { Needs a magnetically } \\
\text { shielded room }\end{array}$ \\
\hline
\end{tabular}

Note: Data from various studies. ${ }^{16-19,22,23,26-28,43,44,122}$

Abbreviations: $\mathrm{fMRI}$, functional magnetic resonance imaging; BOLD, blood oxygen level dependent; ASL, arterial spin labeling; MRI-DTI, magnetic resonance imagingdiffusion tensor imaging; VBM, voxel-based morphometry; NIRS, near-infrared spectroscopy; PET, positron emission tomography; EEG, electroencephalography; ERP, eventrelated potential; MEG, magnetoencephalography.

or chronic pain conditions, an alternative fMRI technique utilizing arterial spin labeling (ASL) is more appropriate. ASL provides a direct measure of cerebral blood flow using magnetically labeled endogenous water in the blood to act as a diffusible tracer. In contrast with BOLD, ASL has reduced temporal resolution but allows for improved quantification of regional blood flow, resulting in better estimation of ongoing blood flow. ${ }^{19}$ fMRI ASL techniques have consequently been used to assess the central processing of pain in patients with migraine ${ }^{20}$ and chronic lower back pain ${ }^{21}$ in different pain states.

Other imaging methods based on magnetic resonance imaging (MRI) that can be used in the study of pain include diffusion tensor imaging (DTI) and structural MRI. DTI uses the diffusion of water in the brain to map white matter. Because water diffuses more rapidly in the direction aligned with the internal structure, DTI elucidates the orientation of white matter tracts as well as imaging functionally localized brain regions to increase our understanding of brain networks $^{22}$ and their connectivity. Structural MRI can provide detailed information about the gray and white matters of the brain and spinal cord. In addition, voxel-based morphometry allows the changes in volume of brain tissue often seen in chronic pain to be measured. ${ }^{23}$ A number of studies have indicated gray matter abnormalities in the PFC, insula, and ACC in patients with chronic pain. ${ }^{24}$

A relatively new technique, near-infrared spectroscopic topographic imaging, works on the same principles as fMRI, in that it continually monitors the blood hemoglobin changes associated with neural activity. While it overcomes the problems associated with having to scan in a magnetically shielded room, and therefore is much more portable, it can 
only be used to scan cortical tissue, whereas fMRI measures activity throughout the brain. ${ }^{25}$

\section{Positron emission tomography}

PET measures changes in metabolism or chemical events at receptor, neurotransmitter reuptake sites in living tissues, or neurotransmitter precursor uptake. ${ }^{26}$ Radionucleotides are used to measure changes in rCBF, blood volume, and oxygen uptake and glucose metabolism (using fludeoxyglucose [FDG]). Of these, $\mathrm{rCBF}$ and glucose metabolism are used to indirectly and directly measure the neuronal response to a painful stimulus, respectively. ${ }^{27,28}$ PET studies using radio-labeled ligands allow the evaluation of receptor occupancy and receptor density. For instance, a well-characterized imaging radioligand can be evaluated in combination with a selective investigational receptor agonist or antagonist competing for the same sites in vivo $^{29,30}$ or in competition with endogenous agonists (Figure 2).

Both BOLD fMRI and FDG-PET (indirectly and directly, respectively) measure neuronal presynaptic activity. ${ }^{31}$ This presynaptic activity may be due to excitation or inhibition, and hence the results need to be interpreted in the context of the cerebral region and its connectivity. In addition, these measures are derived from different pathological processes and, as a result, this can result in differences between the results using the two modalities. Much of the evidence for these differences is derived from animal studies. For example, the signal for gradient-echo BOLD sequences is weighted more toward draining veins and macrovessels, ${ }^{32}$ whereas the FDG-PET signal is weighted toward the tissue compartment. ${ }^{33}$ One animal study has demonstrated that FDG-PET provides a more sensitive measure for brain activation in certain areas of the brain, including the amygdala and IC. ${ }^{34}$
Unlike fMRI, PET incorporates the use of radiation; therefore, the patient exposure should be considered. The glucose analog ${ }^{18} \mathrm{FDG}$ is often appropriate for repeat measures of different pain states measured on separate days over weeks or months. This is due to its relatively short half-life and low effective radiation dose. ${ }^{35}$ This allows repeat imaging in different chronic pain states. Because there is usually good anatomical detail, therefore, reregistration of the brain space over time is relatively good.

FDG measures neuronal activity directly, making it less susceptible to indirect effects of drugs on the cerebral vasculature than indirect methods of functional brain imaging that are dependent on aspects of blood flow or volume.

PET is unique in its ability to evaluate the neurochemical components of central pain processing by using tracers, which directly measure events within the central opioid and dopaminergic systems. This will be further discussed in the later sections of this review. ${ }^{8}$

\section{Electrophysiological studies: electroencephalography and magnetoencephalography}

Both fMRI and PET utilize the hemodynamic response to a change of activity locally in the brain. This is a relatively slow response compared to the speed of the actual neural events. While electrophysiological studies lack good spatial resolution, electrophysiological studies function far better in the temporal domain than fMRI and PET. ${ }^{36}$ As a result, electroencephalography (EEG) and magnetoencephalography (MEG) studies are often used to evaluate separate temporal components of the cerebral pain response, for instance in relation to expectation (Figure 3), that are less well distinguished temporally by other

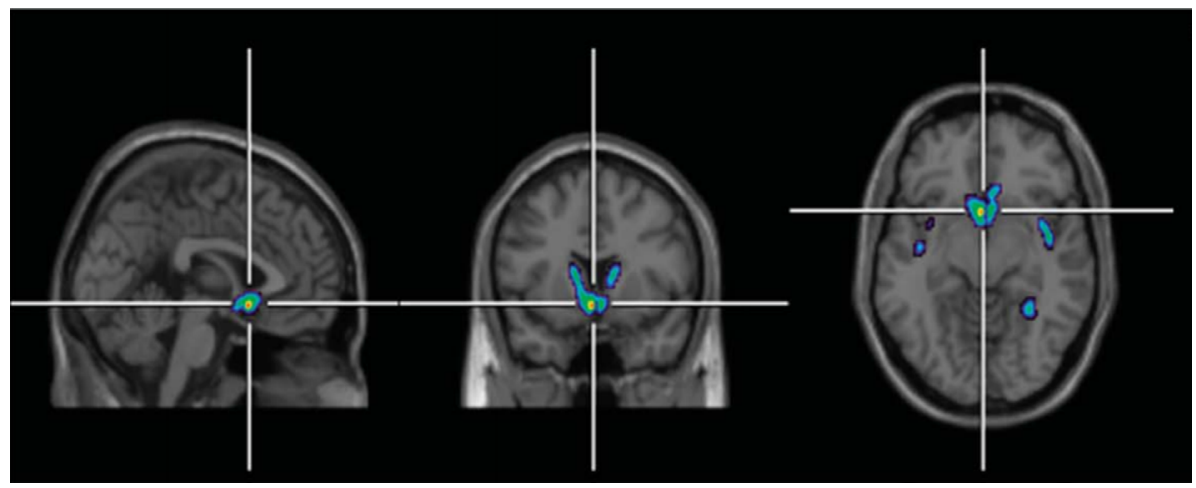

Figure 2 An example figure produced by a neurochemical PET study.

Notes: This diagram was derived from PET imaging of radiotracer "C-diprenorphine, used to illustrate opioid receptor availability, in patients with OA ( $\mathrm{n}=\mathrm{I5}$ ) and rheumatoid arthritis $(n=2)$. Regression analysis was performed using the SPM8 software ${ }^{121}$ to assess the positive relationship between opioid receptor availability and recent McGill pain scores (as a measure of chronic pain over the past week). This diagram illustrates the positive relationship between chronic pain in these patients and opioid receptor binding in the caudate nucleus, nucleus accumbens, and subcallosal area. The highlighted regions indicate regions of significance. Copyright $\bigcirc 2015$ Wolters Kluwer. Reproduced with permission from Brown CA, Matthews J, Fairclough M, et al. Striatal opioid receptor availability is related to acute and chronic pain perception in arthritis: does opioid adaptation increase resilience to chronic pain? Pain. 2015;156(11):2267-2275. Promotional and commercial use of the material in print, digital or mobile device format is prohibited without the permission from the publisher Wolters Kluwer Health. Please contact healthpermissions@wolterskluwer.com for further information.

Abbreviations: PET, positron emission tomography; OA, osteoarthritis. 


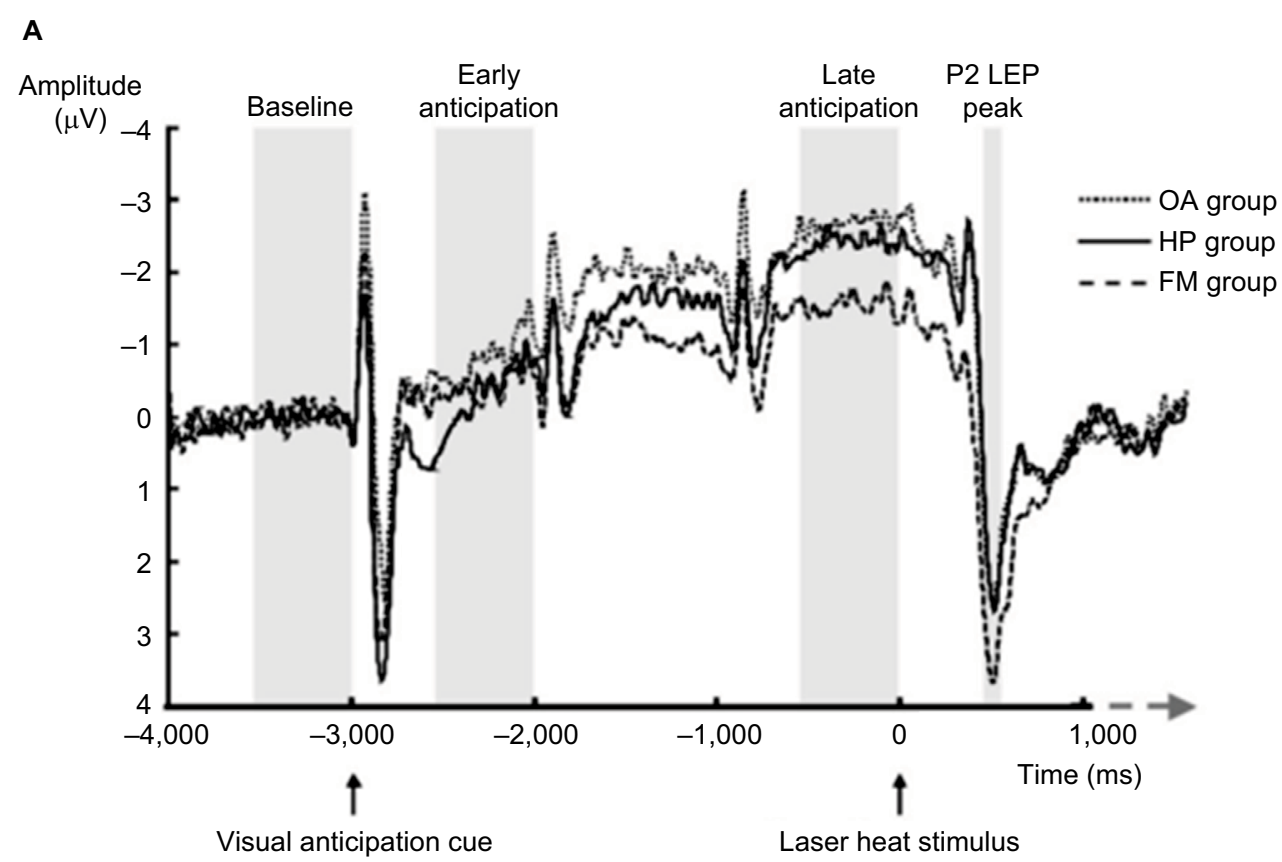

B

Healthy group

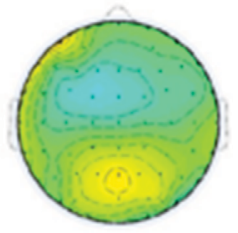

FM group

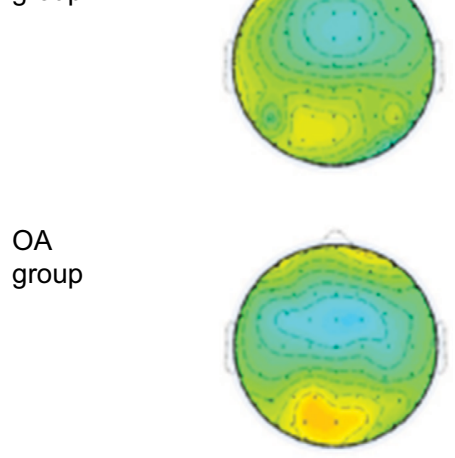

Early anticipation
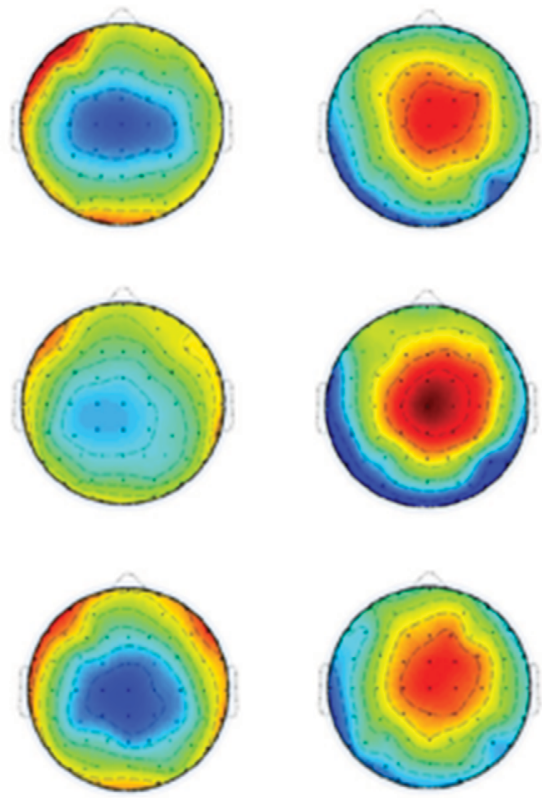

Late anticipation
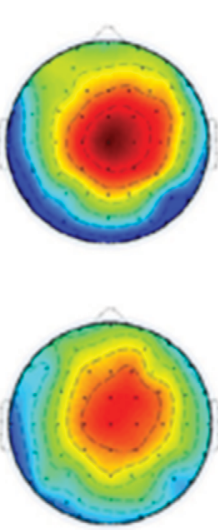

P2 LEP peak

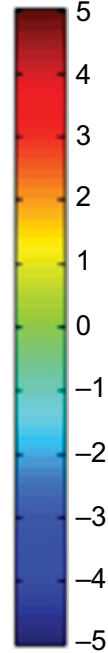

Amplitude

$(\mu \mathrm{V})$

Figure 3 An example figure produced by an EEG study.

Notes: (A) Grand average waveforms for each group. (B) Grand average topographic maps for each group. EEG ERP waveforms and topography plots of experimental heat pain elicited onto patients and healthy volunteers. This diagram illustrates how EEG analysis can be used to split cerebral activation of pain into separate temporal components, early/ late anticipation and the peak evoked by pain. In addition, the topographic maps illustrate the reduced spatial resolution provided by EEG. Red regions indicate areas of increased activation analysis Copyright (C) 2013 Federation of European Neuroscience Societies and John Wiley \& Sons Ltd. Reproduced with Brown CA, El-Deredy W, Jones AK. When the brain expects pain: common neural responses to pain anticipation are related to clinical pain and distress in fibromyalgia and osteoarthritis. Eur J Neurosci. 20I4;39(4):663-672. ${ }^{37}$ Abbreviations: EEG, electroencephalography; ERP, event-related potential; OA, osteoarthritis; FM, fibromyalgia; ms, millisecond; LEP, laser evoked potential.

imaging methods. Processing of first and second pain ${ }^{37-39}$ can also be distinguished using EEG due to the varying conduction times by $\mathrm{A}$ and $\mathrm{C}$ fibers, respectively, and pain anticipation responses. $^{40}$

The EEG signal represents voltage fluctuations from neurons firing in the brain and is recorded from multiple electrodes placed on the scalp. In experimental pain research, a brief noxious stimulus can be time locked to give an event-related potential that provides millisecond accuracy in the timing of pain-related neuronal events. However, EEG has worse spatial resolution than fMRI. These responses can be localized using source analysis, but there is intrinsic 
uncertainty about the accuracy of the sources of the eventrelated potential, due to mathematical analysis of the inverse problem. In order to overcome this, EEG can be combined with fMRI to give accurate temporal and spatial imaging ${ }^{41}$ although this does not truly resolve the fundamental issue because data are being combined from time domains with different temporal resolutions.

One of the fundamental problems that applies to all functional imaging data is that it is dependent on averaging signals over time. This is dependent on assumptions about the stability of the methods over this time. New techniques that are less dependent on signal averaging are being developed to aid this issue, most notably in the context of EEG. ${ }^{42}$

MEG maps brain activity by recording magnetic fields produced by electrical currents that occur when neurons fire. In the same way as EEG, the signals derive from the net effects of currents flowing through neuronal dendrites. Signals are mainly derived from the cortex. MEG provides a better spatial resolution in comparison to EEG; however, it is important to note that source analyses to assess deeper regions are unreliable in both modalities. ${ }^{43}$ The magnetic currents are detected by arrays of superconducting quantum interference devices in a magnetically shielded room. Once the data are collected, source modeling is needed to determine the location of the electrical activity in the brain. As with EEG, MEG's main advantage is within the temporal domain, but it can also accurately pinpoint sources in primary auditory, somatosensory, and motor areas and has been used for pain research. ${ }^{44}$

\section{Mechanisms of pain perception and analgesia}

Functional imaging studies in healthy subjects have revealed a "pain matrix" of structures that can be divided into the medial and lateral pain pathways (Figure 1). The lateral pain pathway is thought to be responsible for the sensory aspects of pain such as location and duration and incorporates SI and SII, parietal operculum (BA7b), and posterior insula. ${ }^{13,45,46}$ The activity within the medial pain pathway is associated with the emotional aspects of pain, such as how unpleasant it is. This medial pain system includes the medial nucleus of the thalamus, the anterior insula, Broadmann area 24 of the ACC, ${ }^{45,47}$ and the PFC (involved in the cognitive appraisal of a stimulus ${ }^{48}$ ).

Pain is not simply an expression of nociception but comprises a multidimensional experience that takes into account psychobiology, attentional processes, and expectations of pain resulting from past and learned pain experiences. The psychological modulation of pain has been well documented. Emotional state is a large factor in how pain is perceived, with negative emotions enhancing pain-evoked activity in the ACC and IC. ${ }^{49}$ Expecting or anticipating pain without an actual physical stimulus is enough to activate pain-related areas of the brain such as the SI, ACC, and $\mathrm{IC}^{13,50}$ and the periaqueductal gray (PAG), PFC, and ventral striatum. ${ }^{37,50-55}$ Using fMRI, healthy subjects given uncertain expectations about painful stimuli developed enhanced transient brain responses to nonpainful stimuli in the ACC and the posterior operculum/posterior insula. ${ }^{55}$ In a later healthy cohort EEG study, expectations about pain intensity biased pain reports toward the expected outcome. Being uncertain about expected heat intensity activated an anticipatory cortical network usually associated with attention. ${ }^{40}$

Expectations and anticipation of pain are also known to be major contributors to placebo analgesia. ${ }^{56}$ Expectationrelated placebo responses lead to activity in the $\mathrm{PFC}^{57,58}$ and cause reduced responses to noxious stimuli in the ACC, ${ }^{59,60}$ IC and thalamus, ${ }^{61}$ and spinal cord ${ }^{62}$ that correlate with the reported relief of pain. From this, it can be concluded that placebo responses affect pain that may be via inhibition of ascending nociceptive pathways inhibiting nociceptive traffic getting to the brain or more directly by increased forebrain executive control of limbic-related areas of the pain matrix. Placebo has been shown to increase endogenous opioid activity on $\mu$-opioid receptors in regions such as the ACC, the dorsolateral prefrontal cortex (DLPFC), the IC, and the nucleus accumbens. ${ }^{63}$ These findings correlated with reduced perception of both sensory and affective components of pain. ${ }^{63}$ Other studies have also drawn parallels between the effect of placebo and exogenous opioids on central pain processing. ${ }^{60}$ Connectivity analysis has identified placebodependent contributions of the rostral anterior cingulate cortex (rACC) activity and the PAG to associated areas of the pain network, the latter being an area central to the descending modulation of pain. ${ }^{64}$

Attending to pain is known to relate to stronger pain impact. ${ }^{65}$ fMRI studies have shown that when subjects take part in an attention-demanding task while experiencing pain, there is decreased pain-related activity in SII, PAG/midbrain, ${ }^{66}$ thalamus, and insula. ${ }^{67}$ What is particularly interesting is how the noise from an MRI scanner can distract subjects enough that it reduces preferentially the unpleasantness of pain and late nociceptive processing. ${ }^{68}$ The complexity of a task will also have an impact on the subjective pain rating. For example, it has been previously demonstrated that while 
activity in the orbitofrontal and medial prefrontal cortices, insula, and cerebellum correlated with the intensity of tonic pain, the demand level of the cognitive task modulated painrelated activity in the medial PFC and cerebellum. ${ }^{69}$

Adaptive changes in the central nervous system due to pain can also be studied using fMRI. Repetitive applications of identical painful stimuli over 8 consecutive days resulted in substantially decreased pain ratings consistent with habituation and decreased BOLD responses to painful stimuli in areas such as the thalamus, insula, and SII, with the observed habituation being mediated by the $\mathrm{rACC} .{ }^{70}$ When this study was followed up after 1 year, the authors found the same response pattern in the $\mathrm{rACC}$, suggesting long-lasting effects of cognitive appraisal. ${ }^{71}$ In another study looking at the effects of repeated noxious stimuli, the repeated noxious stimulation can alter not only the function but also the structure of the brain. Using structural neuroimaging and voxel-based morphometry, gray matter increased in SI, contralateral to the side of stimulation, as well as in the midcingulate cortex and the parietal lobe. ${ }^{72}$

\section{Pain imaging in disease states and during pain relief Altered physiological connectivity}

When compared to healthy controls, chronic pain patients process acute pain in a different way, with what would normally be nonpainful stimuli, often being reported as painful and activating pain-related brain areas. ${ }^{73,74}$ As such, chronic pain patients appear to have altered brain function and structure. ${ }^{75}$ Before the advent of neuroimaging, the structure of the human brain could only be assessed postmortem or by direct observation during neurosurgical procedures. Now, noninvasive structural imaging has provided insight into the pathophysiology of chronic pain syndromes in patients. The central nervous system is known to have neuroplastic properties, ie, it is able to reorganize its neural pathways and synapses. Osteoarthritis (OA) patients show activation of both the medial and lateral pain pathways during experimental and arthritic pain of the same intensity. However, in arthritic pain, there is more activation of the medial system associated with increased unpleasantness of the pain, suggesting that arthritic pain has more emotional salience for OA patients than experimental pain. ${ }^{76}$ During periods of OA pain, there is extensive activation of the cingulate cortex and greater activity in the amygdala, orbitofrontal cortex, and putamen when compared to that during periods of experimental pain. ${ }^{76-78}$ The amygdala, orbitofrontal cortex, and putamen are areas previously associated with aversive conditioning, ${ }^{79}$ reward, and fear, and their activation in OA implies that time activation of this fear-related circuitry is perhaps related to fear of additional injury and disability. ${ }^{80,81}$ In comparison with experimental pain, OA pain is also associated with increased activation of the PFC and the inferior posterior parietal cortex. ${ }^{76,77}$ These regions are associated with the supervision of attention, ${ }^{82}$ and it is hypothesized that descending fibers from the PFC inhibit neuronal coupling along the ascending midbrain-thalamic-cingulate pathway, modulating pain in a "top-down" fashion. . $^{40,83-85}$

Expectations of pain, and the anxiety caused by these expectations, are suggested as a possible source of the increased pain perception seen in chronic pain patients. ${ }^{50,86,87}$ In an EEG study that compared patients with fibromyalgia (FM), patients with OA, and healthy controls, Brown et $\mathrm{al}^{37-}$ demonstrated increased activation of the insula that correlated with the extent of pain and tenderness and decreased activation of the DLPFC that correlated with poor coping during pain anticipation in FM and OA patients compared to controls. It was suggested that this may be a common brain mechanism contributing to pain chronicity in FM and OA. However, the activation of the insula was significantly larger in the FM group than in the OA group and the increased activation correlated with reported pain intensity and the extent of pain. ${ }^{37}$ This suggests that activation by anticipation may modulate the impending pain-evoked activation and pain experience.

Chronic pain often causes changes to the brain that result in pain at sites of the body without tissue damage. This is because prolonged pain can lead to neuroplastic changes at the cortical level, which induce central sensitization. ${ }^{88}$ Chronic pain is often associated with spontaneous pain that has no physical origin and exhibits moment-to-moment variation in pain intensity. ${ }^{89}$ This variation in pain intensity has been used to study the underlying brain circuitry in chronic pain and contrast it with brain activity caused by acute thermal pain. The activations present during periods of rapid increases in pain engaged the anterior insula, which was also activated in healthy controls during acute pain. During periods of high sustained pain, a different circuit involving the PFC and amygdala was engaged..$^{90}$ The amygdala is also known to be activated during attention to pain unpleasantness, ${ }^{45}$ during tonic arthritic pain, ${ }^{76}$ and during high-intensity experimental stimulation. ${ }^{91}$ A recent study showed evidence for the upregulation of opioid receptors in response to chronic pain that correlated with increased pain threshold. ${ }^{92}$ This has long been hypothesized as a homeostatic mechanism for increased resilience to pain. Larger studies need to be 
performed to further evaluate this effect and assess whether relative failure to upregulate these opioid receptors might be related to extreme phenotypes of chronic pain conditions and how we might enhance such compensatory upregulation.

FM patients suffer from widespread chronic pain without a physical cause. As in other chronic pain conditions, FM is often associated with pain catastrophizing and depression. ${ }^{93}$ fMRI has shown that activation patterns in the amygdala can differentiate between FM patients with and without depression. ${ }^{94}$ When the relationship between acute experimental pain and pain-catastrophizing scores was examined using fMRI, catastrophizing was correlated with increased activity in the medial frontal cortex and cerebellum (areas associated with pain anticipation) and the dorsal ACC and DLPFC (areas associated with attention to pain ${ }^{95}$ ).

Neuroimaging has facilitated the observation of volumebased changes that occur in the gray matter of chronic pain patients (for a review, see $\mathrm{May}^{88}$ ). Gray matter volume changes, such as decreases in the DLPFC and the right thalamus, have been seen in chronic back pain patients. ${ }^{96}$ Decreases in gray matter in the DLPFC, somatosensory cortex, and dorsolateral pons and increases in the thalamic gray matter volume have been observed in migraine patients. ${ }^{97}$ Decreases in left parahippocampal gyrus, bilateral mid/posterior cingulate gyrus, left insula, and medial frontal cortex are seen in female FM patients. ${ }^{98}$ In another FM study, gray matter was reduced in postcentral gyrus, amygdala, hippocampus, superior frontal gyrus, and ACC ${ }^{99}$ Interestingly, the decrease seen in the gray matter of chronic pain patients can be reversible. OA patients show decreased gray matter in the thalamus, ACC, and DLPFC, among other areas. However, gray matter volume in the affected cortical areas increases after surgery to alleviate the pain in the damaged joint. ${ }^{100,101}$

Fractional anisotropy (FA) is a scalar measure of relative diffusion anisotropy, which is used as a surrogate measure of microstructural integrity within the brain. DTI analysis of patients with irritable bowel syndrome has shown that patients had lower FA in the thalamus, basal ganglia, and sensory/motor association/integration regions as well as higher FA in the frontal lobe regions and the corpus callosum. ${ }^{102}$ In FM patients, DTI shows decreases in FA in the thalamus and insula and increases in the postcentral gyrus, where SI is located,${ }^{99}$ suggesting more and less effective information transfer, respectively.

\section{Altered neurochemistry}

PET imaging with the radionucleotide ${ }^{11} \mathrm{C}$-carfentanil demonstrated that sustained acute pain triggers the release of endogenous opioids in a region-specific manner and also that a reduction in the severity of pain correlated with increased occupation of $\mu$-opioid receptors by endogenous opioids. ${ }^{105}$ Using ${ }^{11} \mathrm{C}$-diprenorphine, reduced opioid receptor binding has been identified in the cortical and subcortical areas of the brain, including the ACC, insula, and thalamus, in central neuropathic, poststroke pain patients when compared to healthy controls. ${ }^{104,105}$ Reductions in $\mu$-opioid receptor binding in the amygdala, cingulate, and nucleus accumbens have been demonstrated in patients with FM. ${ }^{106}$ In patients with peripheral neuropathic pain, reduced opioid binding is observed bilaterally across brain hemispheres, whereas in those with central neuropathic pain, these reductions in opioid binding are observed in one hemisphere contralateral to pain. ${ }^{107}$ The differences seen in opioid receptor binding between patient groups may reflect different underlying mechanisms of pain and explain the variability seen in response to treatment with opioids. In addition to changes in opioid binding, analysis of the cerebral spinal fluid of FM patients shows a reduced concentration of dopamine. ${ }^{108} \mathrm{PET}$ studies have also demonstrated changes in opioid receptor binding in patients in and out of pain, induced by rheumatoid arthritis and trigeminal neuralgia. These results were consistent with increased competition of opioid receptors by endogenous opioids during ongoing pain. ${ }^{92,109}$ This suggests that the endogenous opioid system is activated by chronic pain and may be susceptible to new potentially centrally acting DENK1 inhibitors. ${ }^{110}$

PET has allowed for the evaluation of potential disruptions in the presynaptic metabolism of dopaminergic neurons and has also demonstrated that dopaminergic activity in the brainstem, thalamus, and parts of the limbic cortex is reduced in FM. ${ }^{111}$

Neuroimaging can also be a useful tool to study the effects of analgesics on the brain. For example, fMRI has been used to investigate the effect of gabapentin on capsaicin-induced and mechanical hyperalgesia. Gabapentin administration reduced activation in the bilateral operculo-IC, independent of the presence of central sensitization, and reduced the activation of the brainstem during central sensitization. ${ }^{112}$ Structural MRI can also be used to look at the effects of analgesic treatments on the brain. After a month of daily opioid administration, chronic back pain patients show decreases in gray matter in the right amygdala and increases in the cingulate (middle, dorsal posterior, and ventral posterior), which are areas known to have high $\mu$-opioid receptor density and binding capacity and strong neural response to opioid administration. ${ }^{113}$ Using structural MRI, DTI, and resting-state fMRI, comparisons between prescription 
opioid-dependent individuals and controls revealed bilateral volumetric loss in the amygdala, decreased anisotropy in axonal pathways specific to the amygdala, and significant decreases in functional connectivity between seed regions that included the anterior insula, nucleus accumbens, and amygdala in opioid-dependent patients. The longer the duration of exposure to prescription opioid, the greater the observed changes in functional connectivity. ${ }^{114}$

\section{Informing pain relief and clinical treatment - future perspectives}

Modern noninvasive human brain imaging has revolutionized the study and treatment of pain. It allows scientists to understand individual differences in response to pain treatments, how endogenous pain relief such as that seen in the placebo response works, and to identify targets for future drug development. Furthermore, studies are now emerging that use neuroimaging as a tool to treat pain and predict pain experience. Real-time fMRI is a technique showing potential as a treatment for chronic pain. ${ }^{115}$ Patients can be trained to use neurofeedback to up- or downregulate the BOLD response to influence the activation of a target brain area, in this case, the ACC or anterior IC. Behavioral pain ratings decreased during feedback, and anterior IC regulation and ACC regulation led to a significant downregulation of parts of the pain network with practice, notably the caudate nucleus. ${ }^{116}$ In another study, subjects learned to downregulate and upregulate the left posterior insula and downregulate the rACC, but this was unrelated to pain intensity or unpleasantness. However, there was a significant increase in pain unpleasantness during upregulation of the left posterior insula when covariation with the rACC was low. ${ }^{117}$

As pain is subjective and pain self-reports can be unreliable in determining pain experience, researchers have been looking for a physiologically based pain assessment that shows a significant correlation with self-reported pain. Neuroimaging is a measure that could work as investigators apply fMRI techniques to pain research. Marquand et $\mathrm{al}^{118}$ showed that multivariate regression models of the Gaussian process were able to predict self-reported, thermally induced pain. In another study, similar techniques were used to predict (with accuracy of $81 \%$ ) whether an individual was experiencing evoked pain or just heat. ${ }^{119}$ Recently, modeling techniques of Marquand et al ${ }^{120}$ have been used to classify chronic low back pain patients from healthy controls with a prediction accuracy of $76 \% .^{120}$

However, in the end, it is the patient's report of pain relief that will determine efficacy of any new therapy. While these methods will provide a more precise understanding of the dynamics of brain connectivity that underpins pain experience, we should be cautious of the concept of a brain scan telling a patient how much pain he or she should be feeling. Philosophically and scientifically, this is probably not tenable and the concept has potential moral side effects in relation to health insurance and other social issues.

\section{Conclusion}

Functional imaging techniques can be broadly split into electrophysiological methods and hemodynamic methods. Electrophysiological methods, EEG and MEG, have unparalleled temporal resolution and so are often used to separate the pain response into temporal components, such as anticipation and early and late response. In comparison, hemodynamic methods, PET and fMRI, have better spatial resolution and therefore are utilized to ascertain specific points of cerebral activation. These techniques have defined key brain structures that comprise the pain matrix consisting of a medial and lateral pain system.

The division of function of these two systems may be broadly defined as related to affective-motivational and sensory-discriminative processing, respectively. The pattern and distribution of activity within the pain matrix is crucially affected by the emotional and cognitive context of experimental pain stimuli, including expectation. More recently, potential mechanisms of chronic pain have been identified in relation to the processing of expectation of pain within the medial pain system, suggesting problems with top-down regulation, particularly involving the interactions between the DLPFC and limbic components of the medial pain system. Neurochemical deficits within the dopaminergic and opioid systems may contribute to some of these candidate mechanisms.

Functional brain imaging has allowed the identification of new candidate brain mechanisms of chronic pain that provide both physiological and pharmacological therapeutic targets for us to collectively develop. It is encouraging that there are new compounds being developed with the potential to modulate some of the control systems in the brain that we think are important for pain perception. ${ }^{110}$ Increased multidisciplinary collaboration with more precise tools for understanding responses within the pain matrix will hopefully result in the development of new and more effective therapies for chronic pain in the next few decades.

\section{Disclosure}

The authors report no conflicts of interest in this work. 


\section{References}

1. Frymoyer JW, Newberg A, Pope M, Wilder D, Clements J, MacPherson B. Spine radiographs in patients with low-back pain. An epidemiological study in men. J Bone Jt Surg. 1984;66(7):1048-1055.

2. Bedson J, Croft PR. The discordance between clinical and radiographic knee osteoarthritis: a systematic search and summary of the literature. BMC Musculoskelet Disord. 2008;9:116.

3. Jensen MC, Brant-Zawadzki MN, Obuchowski N, Modic MT, Malkasian D, Ross JS. Magnetic resonance imaging of the lumbar spine in people without back pain. N Engl J Med. 1994;331(2):69-73.

4. Melzack R. From the gate to the neuromatrix. Pain Suppl. 1999; 6(1):121-126.

5. Melzack R, Wall PD. Pain mechanisms: a new theory. Science. 1965; 150(699):971-979.

6. Lee MC, Mouraux A, Iannetti GD. Characterizing the cortical activity through which pain emerges from nociception. J Neurosci. 2009;29(24):7909-7916.

7. Treede RD. Transduction and transmission properties of primary nociceptive afferents. Ross Fiziol ZhIm IM Sechenova. 1999;85(1): 205-211.

8. Peyron R, Laurent B, García-Larrea L. Functional imaging of brain responses to pain. A review and meta-analysis. Neurophysiol Clin. 2000;30(5):263-288.

9. Moisset X, Bouhassira D. Brain imaging of neuropathic pain. Neuroimage. 2007;37:S80-S88.

10. Obama P. Remarks by the President on the BRAIN Initiative and American Innovation [Internet]. The White House Office of the Press Secretary. 2013 [cited 2015 Dec 14]. Available from: https://www .whitehouse.gov/the-press-office/2013/04/02/remarks-presidentbrain-initiative-and-american-innovation. Accessed July 012016.

11. Parens E, Johnston J. Neuroimaging: beginning to appreciate its complexities. Hastings Cent Rep. 2014;44(S2):2-7.

12. Aguirre GK. Functional neuroimaging: technical, logical, and social perspectives. Hastings Cent Rep. 2014;44(S2):S8-S18.

13. Apkarian AV, Bushnell MC, Treede R-D, Zubieta J-K. Human brain mechanisms of pain perception and regulation in health and disease. Eur J Pain. 2005;9(4):463-484.

14. Fox PT, Raichle ME. Focal physiological uncoupling of cerebral blood flow and oxidative metabolism during somatosensory stimulation in human subjects. Proc Natl Acad Sci U S A. 1986;83(4):1140-1144.

15. Huettel SA, Song AW, McCarthy G. Functional Magnetic Resonance Imaging. 1st ed. Sunderland: Sinauer Associates; 2004.

16. Ogawa S, Lee TM, Kay AR, Tank DW. Brain magnetic resonance imaging with contrast dependent on blood oxygenation. Proc Natl Acad Sci U S A. 1990;87(24):9868-9872.

17. Pauling L, Coryell CD. The magnetic properties and structure of hemoglobin, oxyhemoglobin and carbonmonoxyhemoglobin. Proc Natl Acad Sci US A. 1936;22(4):210.

18. Thulborn KR, Waterton JC, Matthews PM, Radda GK. Oxygenation dependence of the transverse relaxation time of water protons in whole blood at high field. Biochim Biophys Acta. 1982;714(2):265-270.

19. Owen D, Bureau Y, Thomas A, Prato F, Lawrence KS. Quantification of pain-induced changes in cerebral blood flow by perfusion MRI. Pain. 2008;136(1-2):85-96.

20. Kato Y, Araki N, Matsuda H, Ito Y, Suzuki C. Arterial spin-labeled MRI study of migraine attacks treated with rizatriptan. J Headache Pain. 2010;11(3):255-258.

21. Wasan AD, Loggia ML, Chen LQ, Napadow V, Kong J, Gollub RL. Neural correlates of chronic low back pain measured by arterial spin labeling. Anesthesiology. 2011;115(2):364-374.

22. Conturo TE, Lori NF, Cull TS, et al. Tracking neuronal fiber pathways in the living human brain. Proc Natl Acad Sci U S A. 1999;96(18): 10422-10427.

23. Smith SM, Jenkinson M, Johansen-Berg H, et al. Tract-based spatial statistics: voxelwise analysis of multi-subject diffusion data. Neuroimage. 2006;31(4):1487-1505.
24. Davis KD, Moayedi M. Central mechanisms of pain revealed through functional and structural MRI. J Neuroimmune Pharmacol. 2013;8(3): 518-534.

25. Hillman EM. Optical brain imaging in vivo: techniques and applications from animal to man. J Biomed Opt. 2007;12(5):51402.

26. Phelps ME, Hoffman EJ, Mullani NA, Ter-Pogossian MM. Application of annihilation coincidence detection to transaxial reconstruction tomography. J Nucl Med. 1975;16(3):210-224.

27. Phelps ME. Positron computed tomography studies of cerebral glucose metabolism in man: theory and application in nuclear medicine. Semin Nucl Med. 1981;11(1):32-49.

28. Jones AK, Brown WD, Friston KJ, Qi LY, Frackowiak RS. Cortical and subcortical localization of response to pain in man using positron emission tomography. Proc Biol Sci. 1991;244(1309):39-44.

29. Lee CM, Farde L. Using positron emission tomography to facilitate CNS drug development. Trends Pharmacol Sci. 2006;27(6):310-316.

30. Frank R, Hargreaves R. Clinical biomarkers in drug discovery and development. Nat Rev Drug Discov. 2003;2(7):566-580.

31. Jueptner M, Weiller C. Review: does measurement of regional cerebral blood flow reflect synaptic activity? - implications for PET and fMRI. Neuroimage. 1995;2(2PA):148-156.

32. Castillejo-López C, Delgado-Vega AM, Wojcik J, et al. Genetic and physical interaction of the B-cell systemic lupus erythematosus-associated genes BANK1 and BLK. Ann Rheum Dis. 2012;71(1):136-142.

33. Backes H, Walberer M, Endepols H, et al. Whiskers area as extracerebral reference tissue for quantification of rat brain metabolism using (18)F-FDG PET: application to focal cerebral ischemia. J Nucl Med. 2011;52(8):1252-1260.

34. Wehrl HF, Hossain M, Lankes K, et al. Simultaneous PET-MRI reveals brain function in activated and resting state on metabolic, hemodynamic and multiple temporal scales. Nat Med. 2013;19(9):1184-1189.

35. Reivich M, Kuhl D, Wolf A, et al. The [18 F] fluorodeoxyglucose method for the measurement of local cerebral glucose utilization in man. Circ Res. 1979;44(1):127-137.

36. Jones AK, Huneke NT, Lloyd DM, Brown CA, Watson A. Role of functional brain imaging in understanding rheumatic pain. Curr Rheumatol Rep. 2012;14(6):557-567.

37. Brown CA, El-Deredy W, Jones AK. When the brain expects pain: common neural responses to pain anticipation are related to clinical pain and distress in fibromyalgia and osteoarthritis. Eur J Neurosci. 2014;39(4):663-672.

38. Tran T, Inui K, Hoshiyama M, Lam K, Qiu Y, Kakigi R. Cerebral activation by the signals ascending through unmyelinated $\mathrm{C}$-fibers in humans: a magnetoencephalographic study. Neuroscience. 2002;113:375-386.

39. Ploner M, Gross J, Timmermann L, Schnitzler A. Cortical representation of first and second pain sensation in humans. Proc Natl Acad Sci US A. 2002;99:12444-12448.

40. Brown CA, Seymour B, Boyle Y, El-Deredy W, Jones AKP. Modulation of pain perception by expectation and uncertainty: behavioral characteristics and anticipatory neural correlates. Pain. 2008;135(3): 240-250.

41. Liu Z, Ding L, He B. Integration of EEG/MEG with MRI and fMRI. IEEE Eng Med Biol Mag. 2006;25(4):46-53.

42. Olier I, Trujillo-Barreto NJ, El-Deredy W. A switching multi-scale dynamical network model of EEG/MEG. Neuroimage. 2013;83:262-287.

43. Darvas F, Pantazis D, Kucukaltun-Yildirim E, Leahy RM. Mapping human brain function with MEG and EEG: methods and validation. Neuroimage. 2004;23(suppl 1):289-299.

44. Hari R, Salmelin R. Magnetoencephalography: from SQUIDs to neuroscience: neuroimage 20th anniversary special edition. Neuroimage. 2012;61(2):386-396.

45. Kulkarni B, Bentley DE, Elliott R, et al. Attention to pain localization and unpleasantness discriminates the functions of the medial and lateral pain systems. Eur J Neurosci. 2005;21(11):3133-3142.

46. Porro CA, Cettolo V, Francescato MP, Baraldi P. Temporal and intensity coding of pain in human cortex. J Neurophysiol. 1998;80(6): $3312-3320$. 
47. Tolle T, Kaufmann T, Siessmeier T, Lautenbacher S, Berthele A, Munz F. Region-specific encoding of sensory and affective components of pain in the human brain: a positron emission tomography correlation analysis. Ann Neurol. 1999;45:40-47.

48. Brown CA, Huneke NT, Jones AK. Pain Syndromes. Brain Mapping. Elsevier Inc.; 2015:1135-1141.

49. Apkarian AV, Baliki MN, Geha PY. Towards a theory of chronic pain. Prog Neurobiol. 2009;87(2):81-97.

50. Porro CA, Baraldi P, Pagnoni G, et al. Does anticipation of pain affect cortical nociceptive systems? J Neurosci. 2002;22(8):3206-3214.

51. Beydoun A, Morrow TJ, Shen JF, Casey KL. Variability of laser-evoked potentials: attention, arousal and lateralized differences. Electroencephalogr Clin Neurophysiol. 1993;88(3):173-181.

52. Fairhurst M, Wiech K, Dunckley P, Tracey I. Anticipatory brainstem activity predicts neural processing of pain in humans. Pain. 2007;128(1-2):101-110.

53. Hsieh JC, Stone-Elander S, Ingvar M. Anticipatory coping of pain expressed in the human anterior cingulate cortex: a positron emission tomography study. Neurosci Lett. 1999;262(1):61-64.

54. Ploghaus A, Tracey I, Gati JS, et al. Dissociating pain from its anticipation in the human brain. Science. 1999;284(18):1979-1981.

55. Sawamoto N, Honda M, Okada T, et al. Expectation of pain enhances responses to nonpainful somatosensory stimulation in the anterior cingulate cortex and parietal operculum/posterior insula: an eventrelated functional magnetic resonance imaging study. $J$ Neurosci. 2000;20(19):7438-7445.

56. Price DD, Fields HL. The contribution of desire and expectation to placebo analgesia: implications for new research strategies. In: Harrington A, editor. The Placebo Effect: An Interdisciplinary Exploration. Cambridge, MA: Harvard University Press; 1997:117-137.

57. Benedetti F. No prefrontal control, no placebo response. Pain. 2010;148(3):357-358.

58. Watson A, Power A, Brown C, El-deredy W, Jones A. Placebo analgesia: cognitive influences on therapeutic outcome. Arthritis Res Ther. 2012;14(2):206.

59. Kong J, Gollub RL, Rosman IS, et al. Brain activity associated with expectancy-enhanced placebo analgesia as measured by functional magnetic resonance imaging. J Neurosci. 2006;26(2):381-388.

60. Petrovic P, Ingvar M. Placebo and opioid analgesia imaging a shared neuronal network. Science. 2002;295:1737-1740.

61. Wager TD, Rilling JK, Smith EE, et al. Placebo-induced changes in FMRI in the anticipation and experience of pain. Science. 2004;303(5661):1162-1167.

62. Eippert F, Finsterbusch J, Bingel U, Buchel C. Direct evidence for spinal cord involvement in placebo analgesia. Science. 2009;326(5951):404

63. Zubieta J-K, Bueller JA, Jackson LR, et al. Placebo effects mediated by endogenous opioid activity on $\{$ micro $\}$-opioid receptors. J Neurosci. 2005;25(34):7754-7762.

64. Bingel U, Lorenz J, Schoell E, Weiller C, Buchel C. Mechanisms of placebo analgesia: rACC recruitment of a subcortical antinociceptive network. Pain. 2006;120(1-2):8-15.

65. Arntz A, de Jong P. Anxiety, attention and pain. J Psychosom Res. 1993;37(4):423-431.

66. Petrovic P, Petersson KM, Ghatan PH, Stone-Elander S, Ingvar M. Pain-related cerebral activation is altered by a distracting cognitive task. Pain. 2000;85(1-2):19-30.

67. Bantick SJ, Wise RG, Ploghaus A, Clare S, Smith SM, Tracey I. Imaging how attention modulates pain in humans using functional MRI. Brain. 2002;125(pt 2):310-319.

68. Boyle Y, Bentley DE, Watson A, Jones AK. Acoustic noise in functional magnetic resonance imaging reduces pain unpleasantness ratings. Neuroimage. 2006;31(3):1278-1283.

69. Wiech K, Seymour B, Kalisch R, et al. Modulation of pain processing in hyperalgesia by cognitive demand. Neuroimage. 2005;27(1):59-69.

70. Bingel U, Schoell E, Herken W, Buchel C, May A. Habituation to painful stimulation involves the antinociceptive system. Pain. 2007;131(1-2):21-30.
71. Bingel U, Herken W, Teutsch S, May A. Habituation to painful stimulation involves the antinociceptive system - a 1-year follow-up of 10 participants. Pain. 2008;140(2):393-394.

72. Teutsch S, Herken W, Bingel U, Schoell E, May A. Changes in brain gray matter due to repetitive painful stimulation. Neuroimage. 2008;42(2):845-849.

73. Gracely RH, Petzke F, Wolf JM, Clauw DJ. Functional magnetic resonance imaging evidence of augmented pain processing in fibromyalgia. Arthritis Rheum. 2002;46(5):1333-1343.

74. Lawal A, Kern M, Sidhu H, Hofmann C, Shaker R. Novel evidence for hypersensitivity of visceral sensory neural circuitry in irritable bowel syndrome patients. Gastroenterology. 2006;130(1):26-33.

75. Tracey I, Johns E. The pain matrix: reloaded or reborn as we image tonic pain using arterial spin labelling. Pain. 2010;148(3):359-360.

76. Kulkarni B, Bentley DE, Elliott R, et al. Arthritic pain is processed in brain areas concerned with emotions and fear. Arthritis Rheum. 2007;56(4):1345-1354.

77. Parks EL, Geha PY, Baliki MN, Katz J, Schnitzer TJ, Apkarian AV. Brain activity for chronic knee osteoarthritis: dissociating evoked pain from spontaneous pain. Eur J Pain. 2011;15(8):843.e1-843.e14.

78. Gwilym SE, Keltner JR, Warnaby CE, et al. Psychophysical and functional imaging evidence supporting the presence of central sensitization in a cohort of osteoarthritis patients. Arthritis Rheum. 2009;61(9):1226-1234.

79. Seymour B, Doherty JPO, Dayan P, et al. Temporal difference models describe higher-order learning in humans. Nature. 2004;429:664-667.

80. Anderson AK, Phelps EA. Lesions of the human amygdala impair enhanced perception of emotionally salient events. Nature. 2001;411(6835):305-309.

81. Bornhovd K, Quante M, Glauche V, Bromm B, Weiller C, Buchel C. Painful stimuli evoke different stimulus-response functions in the amygdala, prefrontal, insula and somatosensory cortex: a single-trial fMRI study. Brain. 2002;125(pt 6):1326-1336.

82. Posner MI, Petersen SE. The attention system of the human brain. Annu Rev Neurosci. 1990;13:25-42.

83. Lorenz J, Cross DJ, Minoshima S, Morrow TJ, Paulson PE, Casey KL. A unique representation of heat allodynia in the human brain. Neuron. 2002;35(2):383-393.

84. Hadjipavlou G, Dunckley P, Behrens TE, Tracey I. Determining anatomical connectivities between cortical and brainstem pain processing regions in humans: a diffusion tensor imaging study in healthy controls. Pain. 2006;123(1-2):169-178.

85. Lorenz J, Minoshima S, Casey KL. Keeping pain out of mind: the role of the dorsolateral prefrontal cortex in pain modulation. Brain. 2003;126(pt 5):1079-1091.

86. Koyama T, McHaffie JG, Laurienti PJ, Coghill RC. The subjective experience of pain: where expectations become reality. Proc Natl Acad Sci U S A. 2005;102(36):12950-12955.

87. Ploghaus A, Narain C, Beckmann CF, et al. Exacerbation of pain by anxiety is associated with activity in a hippocampal network. $J$ Neurosci. 2001;21(24):9896-9903.

88. May A. Chronic pain may change the structure of the brain. Pain 2008;137(1):7-15.

89. Foss JM, Apkarian AV, Chialvo DR. Dynamics of pain: fractal dimension of temporal variability of spontaneous pain differentiates between pain States. J Neurophysiol. 2006;95(2):730-736.

90. Baliki MN, Chialvo DR, Geha PY, et al. Chronic pain and the emotional brain: specific brain activity associated with spontaneous fluctuations of intensity of chronic back pain. J Neurosci. 2006;26(47):12165-12173.

91. Derbyshire SW, Jones AK, Gyulai F, Clark S, Townsend D, Firestone LL. Pain processing during three levels of noxious stimulation produces differential patterns of central activity. Pain. 1997;73:431-435.

92. Brown CA, Matthews J, Fairclough M, et al. Striatal opioid receptor availability is related to acute and chronic pain perception in arthritis: does opioid adaptation increase resilience to chronic pain? Pain. 2015;156(11):2267-2275. 
93. Edwards RR, Cahalan C, Mensing G, Smith M, Haythornthwaite JA. Pain, catastrophizing, and depression in the rheumatic diseases. Nat Rev Rheumatol. 2011;7(4):216-224.

94. Giesecke T, Gracely RH, Williams DA, Geisser ME, Petzke FW, Clauw DJ. The relationship between depression, clinical pain, and experimental pain in a chronic pain cohort. Arthritis Rheum. 2005;52(5):1577-1584.

95. Gracely RH, Geisser ME, Giesecke T, et al. Pain catastrophizing and neural responses to pain among persons with fibromyalgia. Brain. 2004;127(pt 4):835-843.

96. Apkarian AV, Sosa Y, Sonty S, et al. Chronic back pain is associated with decreased prefrontal and thalamic gray matter density. J Neurosci. 2004;24(46):10410-10415.

97. Schmidt-Wilcke T, Leinisch E, Ganssbauer S, et al. Affective components and intensity of pain correlate with structural differences in gray matter in chronic back pain patients. Pain. 2006;125(1-2):89-97.

98. Kuchinad A, Schweinhardt P, Seminowicz DA, Wood PB, Chizh BA, Bushnell MC. Accelerated brain gray matter loss in fibromyalgia patients: premature aging of the brain? J Neurosci. 2007;27(15):4004-4007.

99. Lutz J, Jager L, de Quervain D, et al. White and gray matter abnormalities in the brain of patients with fibromyalgia: a diffusion-tensor and volumetric imaging study. Arthritis Rheum. 2008;58(12):3960-3969.

100. Gwilym SE, Filippini N, Douaud G, Carr AJ, Tracey I. Thalamic atrophy associated with painful osteoarthritis of the hip is reversible after arthroplasty: a longitudinal voxel-based morphometric study. Arthritis Rheum. 2010;62(10):2930-2940.

101. Rodriguez-Raecke R, Niemeier A, Ihle K, Ruether W, May A. Brain gray matter decrease in chronic pain is the consequence and not the cause of pain. J Neurosci. 2009;29(44):13746-13750.

102. Ellingson BM, Mayer E, Harris RJ, et al. Diffusion tensor imaging detects microstructural reorganization in the brain associated with chronic irritable bowel syndrome. Pain. 2013;154(9):1528-1541.

103. Zubieta JK, Smith YR, Bueller JA, et al. Regional Mu opioid receptor regulation of sensory and affective dimensions of pain. Science. 2001;293(5528):311-315.

104. Jones AK, Watabe H, Cunningham VJ, Jones T. Cerebral decreases in opioid receptor binding in patients with central neuropathic pain measured by [11C]diprenorphine binding and PET. Eur J Pain. 2004;8(5):479-485.

105. Willoch F, Schindler F, Wester HJ, et al. Central poststroke pain and reduced opioid receptor binding within pain processing circuitries: a [11C]diprenorphine PET study. Pain. 2004;108(3):213-220.

106. Harris RE, Clauw DJ, Scott DJ, McLean SA, Gracely RH, Zubieta JK. Decreased central mu-opioid receptor availability in fibromyalgia. $J$ Neurosci. 2007;27(37):10000-10006.

107. Maarrawi J, Peyron R, Mertens P, et al. Differential brain opioid receptor availability in central and peripheral neuropathic pain. Pain. 2007;127(1-2):183-194.
108. Legangneux E, Mora JJ, Spreux-Varoquaux O, et al. Cerebrospinal fluid biogenic amine metabolites, plasma-rich platelet serotonin and $[3 \mathrm{H}]$ imipramine reuptake in the primary fibromyalgia syndrome. Rheumatol. 2001;40(3):290-296.

109. Jones AKP, Kitchen ND, Watabe H, et al. Measurement of changes in opioid receptor binding in vivo during trigeminal neuralgic pain using [11C] diprenorphine and positron emission tomography. J Cereb Blood Flow Metab. 1999;19:803-808.

110. Poras H, Bonnard E, Dangé E, Fournié-Zaluski MC, Roques BP. New orally active dual enkephalinase inhibitors (DENKIs) for central and peripheral pain treatment. J Med Chem. 2014;57(13):5748-5763.

111. Wood PB, Patterson Ii JC, Sunderland JJ, Tainter KH, Glabus MF, Lilien DL. Reduced presynaptic dopamine activity in fibromyalgia syndrome demonstrated with positron emission tomography: a pilot study. J Pain. 2007;8(1):51-58.

112. Iannetti GD, Zambreanu L, Wise RG, et al. Pharmacological modulation of pain-related brain activity during normal and central sensitization states in humans. Proc Natl Acad Sci U S A. 2005;102(50): 18195-18200.

113. Younger JW, Chu LF, D’Arcy NT, Trott KE, Jastrzab LE, Mackey SC. Prescription opioid analgesics rapidly change the human brain. Pain. 2011;152(8):1803-1810.

114. Upadhyay J, Maleki N, Potter J, et al. Alterations in brain structure and functional connectivity in prescription opioid-dependent patients. Brain. 2010;133(pt 7):2098-2114.

115. deCharms RC, Maeda F, Glover GH, et al. Control over brain activation and pain learned by using real-time functional MRI. Proc Natl Acad Sci U S A. 2005;102(51):18626-18631.

116. Emmert K, Breimhorst M, Bauermann T, Birklein F, Van De Ville D, Haller S. Comparison of anterior cingulate vs. insular cortex as targets for real-time fMRI regulation during pain stimulation. Front Behav Neurosci. 2014;8:350.

117. Rance M, Ruttorf M, Nees F, Schad LR, Flor H. Real time fMRI feedback of the anterior cingulate and posterior insular cortex in the processing of pain. Hum Brain Mapp. 2014;35(12):5784-5798.

118. Marquand A, Howard M, Brammer M, Chu C, Coen S, MouraoMiranda J. Quantitative prediction of subjective pain intensity from whole-brain fMRI data using Gaussian processes. Neuroimage. 2010;49(3):2178-2189.

119. Brown JE, Chatterjee N, Younger J, Mackey S. Towards a physiology-based measure of pain: patterns of human brain activity distinguish painful from non-painful thermal stimulation. PLoS One. 2011;6(9):e24124.

120. Ung H, Brown JE, Johnson KA, Younger J, Hush J, Mackey S. Multivariate classification of structural MRI data detects chronic low back pain. Cereb Cortex. 2014;24(4):1037-1044.

121. Ashburner J, Barnes G, Chen C, et al. SPM8 Manual. Functional Imaging Laboratory Institute of Neurology; London, UK; 2012.

122. Harvey AK, Taylor AM, Wise RG. Imaging pain in arthritis: advances in structural and functional neuroimaging. Curr Pain Headache Rep. 2012;16(6):492-501.
Journal of Pain Research

\section{Publish your work in this journal}

The Journal of Pain Research is an international, peer reviewed, open access, online journal that welcomes laboratory and clinical findings in the fields of pain research and the prevention and management of pain. Original research, reviews, symposium reports, hypothesis formation and commentaries are all considered for publication.

\section{Dovepress}

The manuscript management system is completely online and includes a very quick and fair peer-review system, which is all easy to use. Visit http://www.dovepress.com/testimonials.php to read real quotes from published authors. 